\title{
A comparison of methods for temporal analysis of aoristic crime
}

\author{
Matthew PJ Ashby ${ }^{1 *}$ and Kate J Bowers ${ }^{2}$
}

\begin{abstract}
Objectives: To test the accuracy of various methods previously proposed (and one new method) to estimate offence times where the actual time of the event is not known.

Methods: For 303 thefts of pedal cycles from railway stations, the actual offence time was determined from closed-circuit television and the resulting temporal distribution compared against commonly-used estimated distributions using circular statistics and analysis of residuals.
\end{abstract}

Results: Aoristic analysis and allocation of a random time to each offence allow accurate estimation of peak offence times. Commonly-used deterministic methods were found to be inaccurate and to produce misleading results.

Conclusions: It is important that analysts use the most accurate methods for temporal distribution approximation to ensure any resource decisions made on the basis of peak times are reliable.

Keywords: Temporal crime analysis, Aoristic analysis, Temporal accuracy, Peak offence times

\section{Background}

The routine activities approach to explaining crime patterns, first articulated by Cohen and Felson $(1979,590)$, describes how variations in the availability of offenders, targets and guardians explain spatio-temporal variations in crime. When and where there are more offenders, more targets and fewer guardians, there is likely to be more crime (Brantingham and Brantingham 1993, 6). The purpose of this article is to further efforts to analyse these variations by assessing the accuracy of different methods for estimating the most common offence times for certain types of crime for which individual offence times are not known.

Academic interest in developing crime-analysis techniques has focused on spatial variation in crime (Ratcliffe and McCullagh 1998, 752), with less attention being paid to temporal variation. This does not mean that temporal variation is not important: Felson $(2006,7)$ described crime as being "in motion-daily, hourly, and momentarily, on large scale and small", while Felson and Poulsen

\footnotetext{
*Correspondence: matthew.ashby.09@ucl.ac.uk

1 UCL Security Science Doctoral Research Training Centre, 35 Tavistock Square, London WC1H 9EZ, UK

Full list of author information is available at the end of the article
}

$(2003,595)$ noted that the frequency of crime varies more throughout each day than in any other way.

Previous research has shown that the routine activities approach can explain temporal variations in the frequency of many crimes. Temporal variation in crime can be explored on many scales-weekly, monthly and yearly (e.g. Baumer and Wright 1996)-but we focus on variation across the day as our scale of interest here. Melbin $(1978,453)$ noted that the rhythms of crime in Boston followed, but lagged behind, the pattern of routine activities. Cohn $(1993,76)$ found that day of the week, time of day, school vacations and public holidays-which influence people's activities-all predicted the frequency of police calls to deal with domestic violence. Messner and Tardiff $(1985,258)$ found that homicides in which the victim and offender were related to one another were more common at weekends, when people spend more time with family and friends. Cohn and Rotton $(2003,356)$ took this idea further and demonstrated that the frequency and distribution of many types of crime vary substantially on major public holidays, when both offenders and victims are engaged in activities that are different from activities on 'normal' days. These studies all indicate that temporal variation in crime is both substantial and associated with the routine activities of both victims and offenders.

\section{是 Springer}

(C) 2013 Ashby and Bowers; licensee Springer. This is an Open Access article distributed under the terms of the Creative Commons Attribution License (http://creativecommons.org/licenses/by/2.0), which permits unrestricted use, distribution, and reproduction in any medium, provided the original work is properly cited. 
Felson and Poulsen (2003) considered methods for summarising daily variations in crime that would be simple for crime analysts to use. They did not discuss circular statistics, but noted that midnight is a purely arbitrary and somewhat inconvenient 'start' time for a day, since it means that many late-night crimes straddle more than one day. They recommend explicitly choosing an appropriate time at which to 'start' the day for crime analysis purposes, and suggest that 05:00 hours will be suitable in many cases because very few motivated offenders are awake at that time and so little crime happens then.

Felson and Poulsen $(2003,597)$ also recommend a number of summary statistics, including the "median minute of crime" and "crime's daily timespan", the (IQR) around the median. This requires each day to start at a set time: the present study will use 05:00 hours, as Felson and Poulsen $(2003,597)$ suggested.

\section{Aoristic crimes}

Knowing when crime occurs is crucial for crime analysis, but it is also difficult: for certain common types of crime, the crime analyst will usually not know when individual incidents occurred. Ratcliffe and McCullagh (1998, 754) call these "aoristic crimes", using a Greekderived word meaning "indeterminate". The magnitude of the problem of aoristic crimes may be one reason why many police officers appear to know more about where crime happens than when it happens Ratcliffe $(1999,70)$.

Most crimes against unattended property are aoristic, while most crimes against people are not. A victim of a robbery or assault will be able to tell the police more-or-less exactly when the crime occurred Helms (2008, 241), but the victim of a burglary or criminal damage to a motor vehicle will often only be able to state:

1. The time at which they left the property unattended. This is the earliest time at which the crime could have occurred, hereafter known as $t_{\text {start }}$.

2. The time at which they returned to discover the crime had been committed. This is the latest time at which the crime could have occurred, known as $t_{\text {end }}$.

$t_{\text {end }}-t_{\text {start }}=t_{\text {range }}$, the range of times over which the crime could have occurred. Within $t_{\text {range, }}$, the crime actually occurred at an unknown time, $t_{\text {actual }}$. $t_{\text {range }}$ can be a few minutes, a few hours or a few weeks, depending on how long the victim left the property unattended for. The point halfway between $t_{\text {start }}$ and $t_{\text {end }}$ will be known as $t_{\text {mid }}$. This terminology is summarised in Table 1. In each case, the point in time for each crime can be aggregated to form a distribution of that value.
Table 1 Temporal units

\begin{tabular}{ll}
\hline Notation & Temporal unit \\
\hline$t_{\text {start }}$ & The earliest time at which an offence could \\
& have occurred. \\
$t_{\text {end }}$ & The latest time at which an offence could \\
& have occurred. \\
$t_{\text {range }}$ & The period of time between $t_{\text {start }}$ and $t_{\text {end }}$. \\
$t_{\text {mid }}$ & The time halfway between $t_{\text {start }}$ and $t_{\text {end }}$. \\
$t_{\text {random }}$ & A random time between $t_{\text {start }}$ and $t_{\text {end }}$. \\
$t_{\text {actual }}$ & The actual time at which an offence occurred \\
& (usually derived from cCTV). \\
$t_{\text {known }}$ & The actual time at which an offence occurred \\
& if that time was known at the \\
& time the crime was reported to police. \\
& The estimated time (between $t_{\text {start }}$ and $\left.t_{\text {end }}\right)$ \\
$t_{\text {estimate }}$ & that the offence occurred, as calculated by \\
& the various estimation methods. \\
&
\end{tabular}

Table 2 shows $t_{\text {range }}$ for some types of aoristic crime recorded by British Transport Police in 2010. Although crimes do not occur instantaneously (i.e., the criminal event will have a start and end time of its own), the time taken to commit a crime such as burglary or theft from a motor vehicle is so short in comparison to the typical value of $t_{\text {range }}$ (Ratcliffe 1999, 75) that $t_{\text {actual }}$ can be treated as if it were an instant in time rather than an event with its own duration.

\section{Methods for analysing aoristic crimes}

Since $t_{\text {actual }}$ is important but often not known, crime analysts can choose to either ignore temporal variation in crime or use some method to calculate $t_{\text {estimate, the esti- }}$ mated value of $t_{\text {actual }}$. Various estimation methods exist, but it has not previously been possible to establish their relative efficacy because there have been no available data

Table $2 t_{\text {range }}$ for aoristic crimes

\begin{tabular}{|c|c|c|}
\hline Crime type & $\begin{array}{l}\text { Median } \boldsymbol{t}_{\text {range }} \\
\text { (hours:minutes) }\end{array}$ & $\begin{array}{l}\text { Crimes with } \\
t_{\text {range }}>1 \text { hour }\end{array}$ \\
\hline Commercial burglaries & $6: 00$ & $63 \%$ \\
\hline \multicolumn{3}{|l|}{ Criminal damage ... } \\
\hline to motor vehicles & $11: 04$ & $82 \%$ \\
\hline by graffiti & $4: 30$ & $62 \%$ \\
\hline \multicolumn{3}{|l|}{ Thefts ... } \\
\hline of metal & $5: 00$ & $55 \%$ \\
\hline of motor vehicles & $11: 50$ & $88 \%$ \\
\hline from motor vehicles & $10: 00$ & $90 \%$ \\
\hline
\end{tabular}

Source: British Transport Police. 
on the actual distribution of an aoristic crime against which the estimation methods could be compared.

The problems of aoristic crime have, in the authors' experience, led some crime analysts to ignore temporal variation in aoristic crime and not mention it in their analytical products. Such a position can only be justified only if there is no systematic temporal variation in aoristic crime, or if the estimation methods available are so poor that they are misleading.

An alternative to this no-analysis method is to determine a peak time intuitively (Walker 2009, 133), perhaps with a post hoc rationalisation if pressed. Both Ratcliffe and McCullagh (2001) and Bichler and Gaines (2005) found that police officers' intuitive knowledge of where crimes happen was inconsistent. This is likely to be because officers' intuitions are based on their experience of a non-random subset of crime. Since different crimes have different peak times (Grubesic and Mack 2008, 303) and crime patterns change over time (Johnson and Bowers 2004, 58), it appears unlikely that officers will be able to maintain an intuitive picture of when crime occurs (McLaughlin et al. 2007, 103). Although further empirical research on this topic may be valuable, the intuitive method will not be considered further in this study.

The known-time method analyses only those crimes that definitely occurred within one unit of analysis, where the unit of analysis (known as $t_{\text {unit }}$ ) is the level of aggregation at which the data are presented. The time at which the crime occurred for crimes analysed by the known-time method will be referred to as $t_{\text {known }}$. For example, if the object of analysis is to determine the day of the week in which the plurality of crimes occurs, $t_{\text {unit }}=1$ day and the analyst would exclude all crimes that could have occurred in more than one day. Note, however, that this is not the same as saying that crimes are included in the knowntime analysis if $t_{\text {range }}<t_{\text {unit }}$. If (for example) $t_{\text {start }}=23: 01$ hours and $t_{\text {end }}=01: 01$ hours the next day, $t_{\text {range }}=2$ hours $\left(t_{\text {range }} \ll t_{\text {unit }}\right)$ but the crime could have occurred in either of two units of analysis, so the crime cannot be included in any known-time analysis. Ratcliffe $(1999,83)$ points out that this eccentricity will be more problematic if many crimes occur across the boundary of two units of analysis, such as commercial burglaries that occur overnight.

When $t_{\text {unit }}$ is fairly smal l, only a small proportion of crimes will be included in $t_{\text {known }}$, because the average value of $t_{\text {range }}$ for aoristic crimes is much greater than $t_{\text {unit }}$, but $t_{\text {estimate }}$ for those crimes that are included will be relatively accurate (Ratcliffe 1999, 77). Unlike all the other estimation methods, whether the known-time method is a good way of estimating peak offence times depends on whether the crimes included in the distribution of $t_{\text {known }}$ are representative of all crimes (Sorensen 2004, 11).

The known-time method is the only estimation method that reflects the actual behaviour of offenders, rather than extrapolating from $t_{\text {start }}$ or $t_{\text {end }}$, which is more likely to represent the routine activities of victims ${ }^{\mathrm{a}}$. This method should therefore be a good estimator of the actual peak times, subject to the crimes included in the known-time analysis being representative of all crimes.

In the start and end methods, the analyst assumes that every crime occurred at $t_{\text {start }}$ or, alternatively, that every crime occurred at $t_{\text {end }}$. This has the advantage of including every crime in the analysis, but-depending on when the crimes actually occurred-means that the estimated time of each crime can be wrong by anything up to the value of $t_{\text {range. }}$ Since $t_{\text {range }}$ is typically substantial (Table 3), the peak times of $t_{\text {estimate }}$ may be very different from the peak times of $t_{\text {actual }} \cdot t_{\text {start }}$ and $t_{\text {end }}$ reflect the routine activities of the victim (Ratcliffe 2001, 2), as described above, whereas the distribution of $t_{\text {actual }}$ is determined by when (and whether) the routine activities of the offender, target and guardian interact.

The mid-point method assumes that every crime occurred at $t_{\text {mid. }}$. Like the start and end methods, the midpoint method includes every crime in the analysis, but the maximum error in the value of $t_{\text {estimate }}$ is $t_{\text {range }} / 2$. The value of $t_{\text {estimate }}$ generated by the mid-point method should therefore be more accurate than the value generated by the start or end methods (Helms 2008, 242). That said, $t_{\text {mid }}$ is derived solely from $t_{\text {start }}$ and $t_{\text {end }}$, and so it cannot be free of any problems associated with the distributions of $t_{\text {start }}$ and $t_{\text {end }}$.

The start, mid-point and end methods all share a problem: there is no more reason to believe that a crime occurred at $t_{\text {start }}, t_{\text {mid }}$ or $t_{\text {end }}$ than at any other time. A 'random' method (which to the authors' knowledge has not previously been described) could be used to minimise this error by assuming instead that each crime occurred at a random instant within $t_{\text {range, }}$, known as $t_{\text {random. }}$. Although there is no reason to think that any individual crime is more likely to have happened at $t_{\text {random }}$ than at, for example, $t_{\text {start }}$, for a large-enough sample of crimes it appears likely that the distribution of $t_{\text {random }}$ will be more accurate than the distribution of $t_{\text {start }}, t_{\mathrm{mid}}$ or $t_{\mathrm{end}}$.

\section{Table 3 Sample characteristics}

\begin{tabular}{lrr}
\hline & $\begin{array}{r}\text { Original sample } \\
\text { (all crimes) }\end{array}$ & $\begin{array}{r}\text { Final sample } \\
\left(\boldsymbol{t}_{\text {actual }} \text { known }\right)\end{array}$ \\
\hline Crimes & 1,396 & 303 \\
Stations at which & 133 & 70 \\
crimes occurred & 10.5 & 4.3 \\
Crimes per location & $08: 00 \mathrm{hrs}$ & $08: 15 \mathrm{hrs}$ \\
Median $t_{\text {start }}$ & $18: 00 \mathrm{hrs}$ & $18: 00 \mathrm{hrs}$ \\
Median $t_{\text {end }}$ & $11: 30 \mathrm{hrs}$ & $10: 40 \mathrm{hrs}$ \\
Median $t_{\text {range }}$ & &
\end{tabular}


Another way of minimising this error is aoristic analysis. The aoristic method was named and developed by Ratcliffe and McCullagh (1998) with similar methods being described by Gottlieb et al. (1994, 429-434), Rayment (1996, 3), and Brown (1998, 2851). The aoristic method gives each crime a value of 1 and assigns an equal fraction of that value to each unit of analysis in which the crime could have occurred. So if a crime could have occurred in any one of 10 hours, aoristic analysis will assume that there is a probability of 0.1 that the crime occurred in any single hour-long period. The distribution of $t_{\text {aoristic }}$ is the sum of all the fractions allocated from each crime to each hour.

\section{Existing evidence}

Most work on aoristic analysis has been carried out in relation to residential burglary. Ratcliffe and McCullagh (1998, 756-758) showed that aoristic analysis is capable of revealing temporal peaks in burglary levels that were not revealed by known-time analysis. Ratcliffe $(2000,672)$ showed that the temporal distributions produced by the start, mid-point, end and aoristic methods were substantially different from one another. In that study the aoristic method produced a much smoother distribution than the other methods, which all showed a sharply peaked unimodal distribution with the peak at a different time of day. Ratcliffe $(2001,2)$ noted that these peaks reflect the routine activities of the burglary victims, in that the peak in $t_{\text {start }}$ occurred when most people left their house for work and the peak in $t_{\text {end }}$ occurred when most people returned home.

Ratcliffe $(2002,33)$ showed that there was a significant correlation between the distribution of $t_{\mathrm{start}}, t_{\text {mid }}$, $t_{\text {end }}$ and $t_{\text {aoristic }}$ for offences where the mean value of $t_{\text {range }}$ was less than four hours $\left(\bar{t}_{\text {range }}<4 t_{\text {unit }}\right.$, where $t_{\text {unit }}=1$ hour), for example assaults, personal robberies and possession of drugs. For domestic burglaries, for thefts of and from motor vehicles, and for criminal damage there was no correlation between $t_{\text {start }}$ or $t_{\text {end }}$ and $t_{\text {aoristic }}$, although the correlation between $t_{\text {mid }}$ and $t_{\text {aoristic }}$ remained. What these findings could not show, however, was which estimation method most accurately reflected $t_{\text {actual }}$, since $t_{\text {actual }}$ was not known.

\section{Representing time in crime analysis}

Time is usually considered to be linear (Fitzpatrick 2004, 200): 13:10 hours on Saturday 17 January 1981 occurred before 16:00 hours on Thursday 15 September 2011, and neither moment will recur (at least in the Gregorian calendar). In other ways, however, time is circular: 15 September will recur every year, Thursday every week, and 16:00 hours every day (the rhythms of time described by Hawley 1950, 289).
Although crime varies over time in cycles, researchers typically treat these variations as if they were linear (for typical examples, see Nelson et al. 2001, Ratcliffe 2002 and Townsley et al. 2000). Brunsdon and Corcoran (2006) suggested using circular statistics to better represent temporal crime cycles. These are a class of graphical and statistical methods that have been developed to handle data that are circular or cyclical (Berens 2009, 1). There are many examples of data that are inherently circular, such as wind directions, magnetic fields and migration patterns, as well as time (Fisher 1993, chapter 1). Special methods are required when dealing with circular data because any point around the circle can be chosen as 'zero', concepts such as 'before' and 'after' are often meaningless, and because there are two ways (clockwise around the circle or anticlockwise) to measure the distance between any two points (Jammalamadaka and SenGupta 2001, 1-3). Using linear statistics on cyclical data can give misleading results (Mardia 1972, xviii), so this study used statistical methods developed for use with circular data.

\section{The present study}

The present study considered the different estimation methods described above from the point of view of a local police crime analyst studying everyday crime, since that is what most crime analysts do (O'Shea and Nicholls 2003, 7). The key consideration in judging the validity of the data and methods used here should be whether or not they reflect the circumstances typically faced by a police agency crime analyst.

This study used data on theft of pedal cycles from railway stations, which are aoristic (median $t_{\text {range }}$ or $\tilde{t}_{\text {range }}=$ 11 hours, $t_{\text {range }}>1$ hour for $95 \%$ of offences) but which are often captured on CCTV. This allows the (motivated) investigating officer to determine $t_{\text {actual }}$ precisely. Since $t_{\text {actual }}$ becomes known from CCTV only after the victim has reported $t_{\text {start }}$ and $t_{\text {end }}$, cycle thefts captured on CCTV can be used to compare the distribution of $t_{\text {actual }}$ with the distribution of $t_{\text {estimate }}$ produced by each estimation method.

The central aim of this study was to determine which estimation method best predicted the distribution of $t_{\text {actual }}$. Within that aim, the study sought answers to a number of questions:

1. What was the distribution of $t_{\text {actual }}$ ?

2. What distribution of $t_{\text {estimate }}$ did each method produce?

3. Which estimation method best predicted $t_{\text {actual }}$ ?

The answers to these questions raised supplementary questions about optimisation of the different estimation methods: 


\section{Under what conditions is $t_{\text {known }}$ a good approximation of $\boldsymbol{t}_{\text {actual? }}$ ?}

Ratcliffe $(2002,33)$ showed that it is not necessary to use methods suitable for analysing aoristic crimes if $\bar{t}_{\text {range }}<$ $4 t_{\text {unit }}$, indicating that it is not necessary to know $t_{\text {actual }}$ for every crime in order to produce a reliable estimated distribution. In other words, $t_{\text {known }}$ can approximate $t_{\text {actual }}$ in certain conditions. This leads to a related question: when $\bar{t}_{\text {range }}>4 t_{\text {unit }}$ and it is possible (with additional work) to identify $t_{\text {actual }}$ for a random sample of crimes, for what proportion of crimes must $t_{\text {actual }}$ be determined in order to make the resulting distribution (i.e. $t_{\text {known }}$ ) a good approximation of the true distribution of $t_{\text {actual }}$ ?

\section{Should all crimes be included in aoristic analysis?}

Ratcliffe $(2000,675)$ noted that aoristic analysis is complicated by crimes for which $t_{\text {range }}$ is greater than 24 hours, while Gottlieb et al. $(1994,417)$ suggested that such crimes be removed before estimating $t_{\text {actual }}$ by any method. This was suggested in order to make computation easier, but also because a crime for which $t_{\text {range }}=24$ hours would have an aoristic value of $1 / 24=0.042$, so that the crime would contribute little to the distribution of $t_{\text {aoristic }}$.

\section{Methods}

\section{Data}

British Transport Police (BTP), the railway police force for Great Britain, provided 1,396 reports of pedal cycle thefts from 133 railway stations in three areas north of London for the calendar year 2010. Each report included $t_{\text {start }}$ and $t_{\text {end }}$ as well as details of the investigating officer's efforts to identify the offender.

$t_{\text {actual }}$ was determined by one of the authors reading each crime report and, where necessary, associated intelligence reports and prosecution files. The wide availability of CCTV at United Kingdom (UK) railway stations (McCahill and Norris 2003, 13) means that BTP officers are able to investigate almost all cycle thefts. However, even when CCTV systems are installed their recordings are not always available, for example because of technical faults or the wrong images being retrieved. CCTV images of the crime scene were available in $59 \%$ of cases, but not all of these recordings showed the crime happening, and in some cases the quality was too poor to allow the officer to identify one pedal cycle from another.

Taking these factors into account, officers could see the offence happening on CCTV (and therefore determine $t_{\text {actual }}$ ) in $22 \%$ of cases (303 out of 1,396$)$, from 70 different stations. This included 26 cases in which the suspect had either been arrested while stealing the bike or a witness had seen the theft happen. These 26 cases were those that were available to include in the knowntime analysis.
Since $t_{\text {actual }}$ could not be determined in $78 \%$ of cases, three questions emerged:

1. Is the number of remaining crimes, for which $t_{\text {actual }}$ is known, a large enough sample for use?

2. Are the crimes for which $t_{\text {actual }}$ is known a representative sample of all crimes?

3. Is it reasonable to aggregate crimes from different stations into one sample?

\section{Sample size}

In most agencies, a crime analyst will have relatively few aoristic crimes to analyse: in 2010, the mean number of burglaries recorded in United States (US) cities was 158 (Federal Bureau of Investigation 2011, derived from Table eight). In England and Wales, crime analysis is typically done in one of 190 basic command units, which have a mean of 95 burglaries per month (Home Office 2011). The present sample of 303 crimes over one year thus appears sufficient for use in assessing the suitability of the different estimation methods for use in tactical analysis.

\section{Sampling bias}

The median $t_{\text {start }}$ and $t_{\text {end }}$ for the original and final samples were similar (Table 3), suggesting that the distribution of the final sample will be a good approximation of the original for estimating $t_{\text {actual }}$, since all the methods except the known-time method are based on $t_{\text {start }}$ and $t_{\text {end }}$. The crimes in the final sample of 303 crimes occurred at a subset of stations in the original sample, possibly because some stations had outdated or poor-quality CCTV systems.

It is unlikely that a local crime analyst will ever be sure that their crime data represent a random sample of all relevant crimes. Hoare $(2011,76)$ found that only $39 \%$ of cycle thefts were reported to the police, while Barclay and Tavares $(1999,6)$ found that the police did not record many of the cycle thefts reported to them. Victim surveys routinely find more crimes than are recorded by the police (Skogan 1974, 30), but surveys are time-consuming and expensive (Tilley 1995, 7), putting them beyond the resources of most agencies. Recorded crime statistics are a low-cost byproduct of the investigative process (Lewis $1992,15)$, and so they will inevitably be the primary data for most agencies.

\section{The ecological fallacy}

The 303 crimes in the final sample occurred over a period of a calendar year at 70 geographically distant railway stations. Treating them as one unit risks (a) obscuring temporal variations and (b) producing a crime distribution that is accurate for the area overall but inaccurate for each location or smaller group of locations. Conversely, the smaller the number of locations (and therefore crimes) 
included, (a) the more likely the sample is to be biased in some way (Spatz Widom 1989, 160) and (b) the more difficult it is to conduct meaningful statistical tests (Brown $1989,116)$. Is it reasonable to treat the final sample as if it were drawn from a homogeneous population to which the ecological fallacy would not apply?

To answer this question, the offences in the final sample were grouped into seven geographical policing areas. Between areas, it is only necessary to determine whether the distributions of $t_{\text {start }}$ and $t_{\text {end }}$ were similar (Figure 1), because all estimation methods but the known-time method derive $t_{\text {estimate }}$ from these two values. Figure 1 shows these distributions as linear box plots starting at midnight, because circular box plots are difficult to interpret (Abuzaid et al. 2012). The median $t_{\text {start }}$ and $t_{\text {end }}$ for each area are similar. When the areas are clustered into three similar-sized groups, a Wheeler-Watson test (described further below) showed the distributions of each group to be homogeneous $\left(W_{r}=0.06\right.$ for Group I and Group II, $W_{r}=0.15$ for Group II and Group III). This suggests that it is reasonable to treat the final sample as a single group.

\section{Tools}

Techniques for analysing circular data are not included in most statistical packages. One exception is the $\mathrm{R}$ language (http://www.r-project.org/), for which there are two sets of functions that analyse circular statistics. In the present study, the CircStats package was used for data analysis and the Circular package for graphical presentation. Non-circular analysis was done with the $\mathrm{R}$ language and the SPSS version 17. Aoristic analysis was carried out in a program written by one of the authors in PHP (http://www.php.net/) for this purpose.

\section{Statistical methods}

A test was required to determine whether the frequency of crime varied non-randomly over time. Jammalamadaka and SenGupta $(2001,132)$ caution against assessing uniformity visually, so Rayleigh's test was used. This is a non-parametric test in which the null hypothesis is that the sample is drawn from a uniform circular distribution and the alternative hypothesis is that it is drawn from a unimodal distribution of unknown mean value (Moore 1980, 175).

Tests were necessary to determine the relationship between the distribution of $t_{\mathrm{actual}}$ and the distribution of $t_{\text {estimate }}$ produced by each method. Since the samples are not normally distributed, we used the test described by Wheeler and Watson (1964), test statistic $W_{r}$, as recommended by Fisher $(1993,123)$. The Wheeler-Watson is a non-parametric two-sample test in which the null hypothesis is that the two temporal samples have the same distribution. The Wheeler-Watson test is an extension of an earlier test proposed by Watson $(1961,1962)$, for which

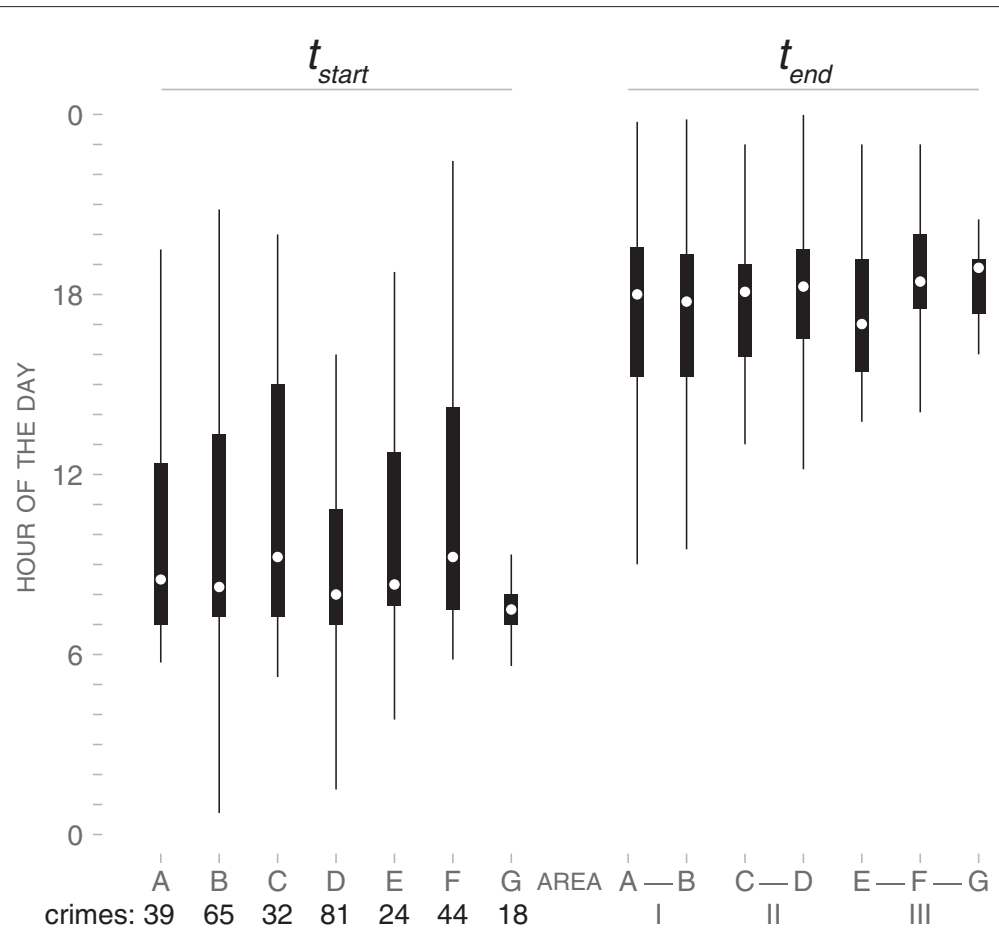

Figure $1 t_{\text {start }}$ and $t_{\text {end }}$ are broadly homogeneous in different geographical areas. 
Berens $(2009,13)$ states that the bin-width for aggregate data should be no more than $10^{\circ}$. $t_{\text {unit }}$ for the aoristic analysis was therefore set at 30 minutes, equivalent to $7.5^{\circ}$. To investigate the possibility of an ecological fallacy further, the Wheeler-Watson tests were run both for the whole study area and for each group of stations (I, II and III).

To compensate for any possible problem with comparing samples of different sizes, the distribution of $t_{\text {known }}$ $(n=26)$ was compared against both the whole sample of $t_{\text {actual }}$ and against a sample of 26 crimes taken randomly from $t_{\text {actual }}$. The comparison of samples of 26 crimes was run 1,000 times and the mean value of the test statistic taken. To ensure that the random times generated for each crime did not produce an anomalous distribution of $t_{\text {random }}, 100$ randomly generated distributions were tested and the mean value of the test statistic taken.

The Wheeler-Watson test indicates whether two distributions are homogeneous or not, but gives no indication of how they differ. To investigate the differences, offences were aggregated into one-hour categories and the predicted number of offences in each category compared to the number of offences that actually occurred in that hour. These residual values were standardised to allow comparison between estimation methods. $z>|2|$ is often considered significant (Harvill 1991, 36) because $-1.96<$ $z<+1.96$ for $95 \%$ of normally-distributed observations. However, since there were 24 residuals for each method, one or more were likely to produce $z>|2|$ by chance and so $z>|3|$ (approximate to $p=0.001$ ) was considered significant.

Monte Carlo simulation was used to determine the conditions under which $t_{\text {known }}$ would be a good approximation of $t_{\text {actual }}$, following a model suggested by Ratcliffe $(2004,66-69)$ in dealing with a similar problem. One percent of crimes were removed at random from the sample of 303 crimes and the resulting distribution was compared against the entire $t_{\text {actual }}$ distribution using the WheelerWatson test. If the two distributions were homogeneous, a further $1 \%$ of crimes were removed and the test repeated. This procedure continued until the two distributions were significantly different at the $p=0.05$ level. The procedure was then repeated 1,000 times to generate a reasonable sample.

To test whether excluding crimes where $t_{\text {range }}>24$ hours would alter the distribution of $t_{\text {aoristic }}$, that distribution was tested against a modified distribution from which crimes where $t_{\text {range }}$ exceeded a certain number of hours had been removed. This process was repeated using progressively smaller threshold values of $t_{\text {range, }}$, until the unmodified and modified distribution were found not to be homogeneous. Rao's test of homogeneity (SenGupta and Rao 1966, 172-173) - a parametric test of whether two distributions have the same mean value and variance-was used for this purpose. This test can be used to compare any data in which each sample is of reasonable size and approximately normally distributed, as was $t_{\text {aoristic }}$ in this case $(\bar{r}=0.457, p<0.001)$.

\section{Results}

What is the distribution of $t_{\text {actual }}$ ?

Figure 2 shows the distribution of $t_{\text {actual }}$ by time of day. The times of individual offences are shown as dots on the circumference of the circle, stacked where necessary. Inside the circle, 05:00 hours (the 'start' of the day for the purposes of Felson-Poulsen statistics) is shown by an elongated tick mark, along with a white dot illustrating the median minute of crime and a grey bar to show the daily timespan (IQR) of crime. Specimen police shifts, which are commonly eight-hours long (Accenture 2004, 18) and start at 07:00 hours, 15:00 hours and 23:00 hours (Rengert 1997, 206), are also shown.

The Rayleigh test showed that the distribution of $t_{\text {actual }}$ was significantly non-uniform $(\bar{r}=0.458, p<0.001)$, so the null hypothesis of a uniform distribution was rejected. Figure 2 shows that half of pedal cycle thefts happen between 13:04 and 18:52 hours. The daily timespan of 5 hours 47 minutes suggests that cycle theft can be dealt with by teams of officers working a single 8-hour shift centred around the median minute: 15:22 hours.

The distribution of $t_{\text {actual }}$ is an estimate of the true population distribution of crimes. One common non-parametric method of estimating the underlying population density from a sample is kernel density estimation (KDE) (Buskirk 1998, 799). KDE generates a continuous distribution from a sample of discrete events, and

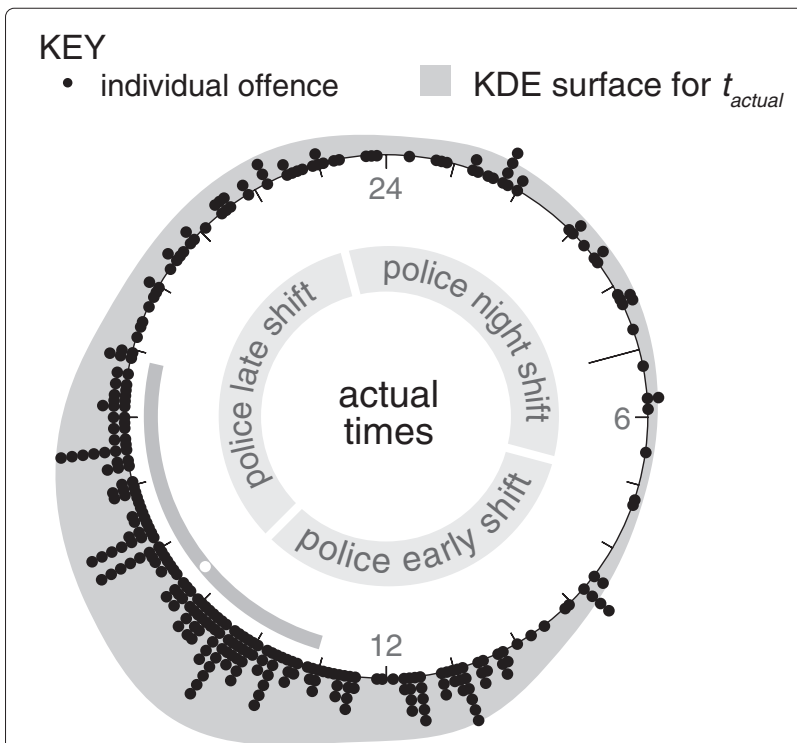

Figure 2 The distribution of $t_{\text {actual }}$ is broadly unimodal around the median time of 15:22 hours. 
has been adapted for use with circular data (Brunsdon and Corcoran 2006, 309). KDE was used in the present study to illustrate the population distribution of crime predicted by each estimation method.

KDE relies on the operator to choose a suitable smoothing parameter, known as the bandwidth (Jones et al. 1996, 401). The choice of bandwidth has a substantial effect on the results of the KDE process (Chiu 1996, 129), and there is extensive literature on choosing the most appropriate bandwidth for linear data sets (see Turlach 1993, for a review). Density estimation of circular data is less common (Di-Marzio et al. 2011, 2156), and the present authors were unable to find any empirically-based suggestions for choosing an appropriate bandwidth. This study followed the lead given by Brunsdon and Corcoran $(2006,309)$ in adopting a 'trial and error' approach, with the aim of ensuring that the resulting (KDE) distribution appears visually to be neither under- nor over-fitted. The resulting KDE is shown in Figure 2 and demonstrates that the distribution of $t_{\text {actual }}$ is broadly unimodal around the mean time of 15:22 hours.

\section{What distribution of $t_{\text {estimate }}$ does each method produce?}

Figure 3 shows the offence times predicted by each method and the resulting (KDE) surface, superimposed upon the (KDE) surface for $t_{\text {actual }}$. Table 4 shows the Felson-Poulsen statistics for each method. The aoristic and random methods predict the median minute most accurately and predict the daily timespan (IQR) to within one hour. The mid-point method comes next, although the median minute is almost two hours earlier than the actual median minute, and the daily timespan is more than two hours longer. The distributions of $t_{\text {start }}, t_{\text {mid }}$ and $t_{\text {end }}$ are clearly unimodal; the distributions of $t_{\text {random }}$ and $t_{\text {aoristic }}$ less so; and the distribution of $t_{\text {known }}$ is apparently bimodal.

\section{Which estimation method best predicts $t_{\text {actual }}$ ?}

Table 5 shows the results of Wheeler-Watson tests comparing the distribution of $t_{\text {actual }}$ and each distribution of

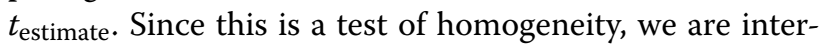
ested in those methods for which there is insufficient evidence to reject the null hypothesis. All the distributions other than the known-time distribution appear not to be homogeneous with $t_{\text {actual, }}$, although the values of $W_{r}$ for $t_{\text {random }}$ and $t_{\text {aoristic }}$ are much smaller than for the deterministic estimation methods and appear to be close to homogeneous with $t_{\text {actual }}$.

The Wheeler-Watson results suggest that the $t_{\text {known }}$ distribution is homogeneous with $t_{\text {actual }}$ regardless of differences in sample size. While this indicates that $t_{\text {known }}$ should be a good predictor of $t_{\text {actual, }}$, the differences between these two distributions shown in Figure 3 suggests that they are not homogeneous. Given that there were only 26 crimes in the $t_{\text {known }}$ distribution, that they are not drawn randomly from the underlying population of crimes and that their distribution is apparently bimodal, the result of the Wheeler-Watson test in this case should be treated with caution.

Figure 4 shows how the distribution of $t_{\text {estimate }}$ produced by each method differed from the distribution of $t_{\text {actual }}$ for each hour. The standardised residuals are presented in a linear format starting at midnight, because it is difficult to present negative values clearly in circular form. The start, mid-point and end methods significantly overestimate the occurrence of crimes in the early morning, early afternoon and evening respectively. The residuals of the random and aoristic distributions are very similar, and much smaller than those for the other methods, with no residual $>|3|$.

\section{Optimal deployment of police resources}

It will not always be necessary for a crime analyst to know the precise distribution of $t_{\text {actual }}$ in order to recommend when officers should be deployed to deal with a particular crime problem. To illustrate a simpler method than either the Wheeler-Watson test or analysis of residuals, it was assumed that an analyst had been asked to recommend a four-hour time period (half a standard police shift) for which officers should be deployed, and that for simplicity that period should start and end on the hour or on the half-hour. If the analyst had a priori reasons to believe that the crime was normally distributed in time, he or she could simply take the median minute of crime described by Felson and Poulsen $(2003,597)$, round it to the nearest half-hour, and take that as the middle of the deployment time. The accuracy of this procedure, using the median minute for each estimation method, was measured by considering what proportion of the four-hour period overlapped with the four-hour period suggested by the distribution of $t_{\text {actual }}$.

Table 6 shows the results for each estimation method, and confirms the order of accuracy found above, with the aoristic method predicting a period that contained the same proportion of crimes as the actual optimum fourhour period. The start and end methods predicted very little.

\section{Supplementary questions}

\section{When is $t_{\text {known }}$ a good approximation of $t_{\text {actual }}$ ?}

The Monte-Carlo analysis showed that the mean proportion of crimes for which $t_{\text {actual }}$ must be known in order for the distributions of $t_{\text {known }}$ and $t_{\text {actual }}$ to be homogeneous was $5.2 \%$ of crimes, with a standard deviation of $2.6 \%$. To ensure that any recommended minimum sample size will be sufficient on $95 \%$ of occasions, Ratcliffe $(2004,69)$ recommends setting the minimum at the mean plus two standard deviations, in this case $10.4 \%$ of crimes. However, this is an estimate of the 
minimum acceptable sample size, and should be treated with caution: the actual minimum size will depend on the unknown factors that drive the temporal distribution of crime.

\section{Should all crimes be analysed by the aoristic method?}

Testing for progressively smaller maximum values of $t_{\text {range }}$ showed that the mean values of $t_{\text {aoristic }}$ were homogeneous until crimes where $t_{\text {range }} \geq 47$ hours were excluded
( $H=4.179, p<0.05)$, and that the variances were homogeneous until crimes where $t_{\text {range }} \geq 76$ hours were excluded $(H=3.970, p<0.05)$.

As a final test for sample bias, the distributions of $t_{\text {estimate }}$ based on the final sample for which $t_{\text {actual }}$ was known $(n=303)$ and those based on the original sample of cycle thefts $(n=1,396)$ were compared using the Wheeler-Watson test, as shown in Table 7. Each pair of distributions was homogeneous except the mid-point

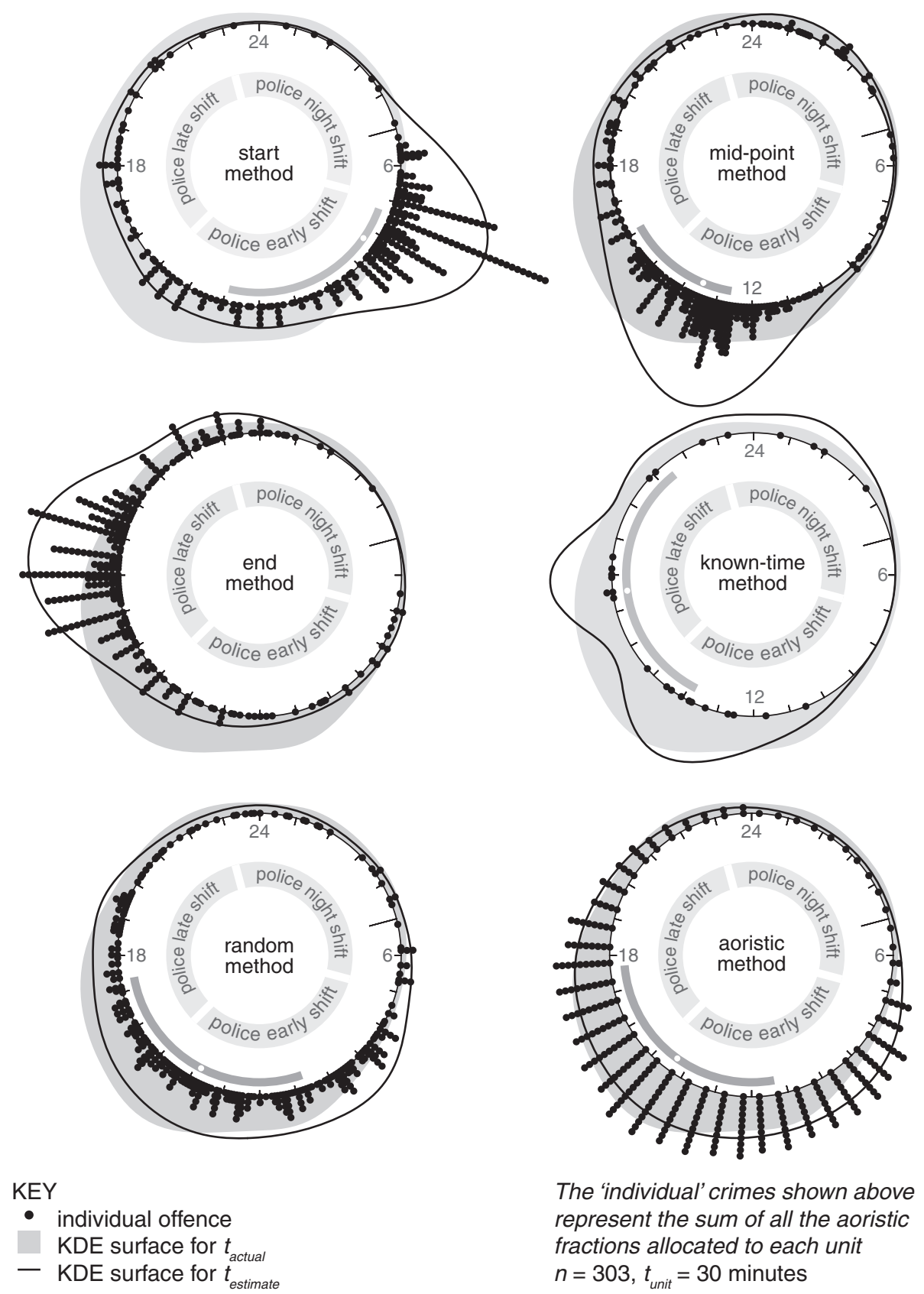

Figure 3 The distributions of $t_{\text {estimate }}$ produced by different methods. 
Table 4 Summary of estimation-method statistics

\begin{tabular}{|c|c|c|c|c|c|}
\hline \multirow[b]{2}{*}{ Method } & \multirow[b]{2}{*}{ Distribution } & \multicolumn{2}{|c|}{ Median minute } & \multicolumn{2}{|c|}{ Daily timespan } \\
\hline & & Value & Diff. & Value & Diff. \\
\hline Actual & $t_{\text {actual }}$ & 15:22 & - & $5: 47$ & - \\
\hline Start & $t_{\text {start }}$ & 08:20 & $-7: 02$ & $5: 35$ & $-0: 12$ \\
\hline Mid-point & $t_{\text {mid }}$ & 13:30 & $-1: 52$ & $3: 30$ & $-2: 17$ \\
\hline End & $t_{\text {end }}$ & 18:15 & $+2: 53$ & 3:05 & $-2: 42$ \\
\hline Known-time & $t_{\text {known }}$ & $17: 31$ & $+2: 09$ & 7:41 & $+1: 54$ \\
\hline Random & $t_{\text {random }}$ & 13:49 & $-1: 33$ & $6: 38$ & $+0: 51$ \\
\hline Aoristic & $t_{\text {aoristic }}$ & $14: 23$ & $-0: 59$ & $6: 23$ & $+0: 35$ \\
\hline
\end{tabular}

method, for which the test statistic was very close to the critical value of $W_{r}=0.18$.

\section{Discussion}

Which estimation method should crime analysts use?

The aoristic and random methods produced the distributions of $t_{\text {estimate }}$ that were closest to being homogeneous with the distribution of $t_{\text {actual }}$, and neither significantly over- or under-estimated the frequency of crime in any hour of the day. Both methods appear suitable for use in the temporal analysis of aoristic crime. All crimes, even those with a long $t_{\text {range }}$ should be included.

Alone among the estimation methods, the aoristic method does not assume that each crime happened at a particular time-this may explain the apparent predictive power of aoristic analysis. The random method does make this assumption, but recognises that there is no way to know which particular time is correct. The cost of this approach is that it requires a sample of sufficient size to reduce the chance of clustering in the random times chosen. The random method is therefore likely to be less useful for small samples. Furthermore, the distribution produced by the random method is likely, with increasing $n$, to tend towards the results of the aoristic method. Since repeating the random method analysis, as was done here, can be computationally intensive, it may be wise to recommend the aoristic method for everyday crime analysis.

Aoristic analysis is not unproblematic. As $t_{\text {range }}$ grows, the aoristic fraction will asymptotically approach zero, so that a crime with a very large $t_{\text {range }}$ will contribute very little to the distribution of $t_{\text {aoristic }}$, which-if there are enough such crimes-will become very smooth. Conversely, if (for a particular crime) $t_{\text {range }} \leq t_{\text {unit }}$, the aoristic fraction will approach 1 . In a small sample, this could create a temporal peak that outweighs several crimes with a

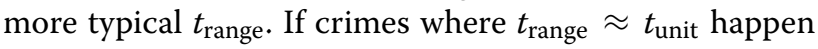
more often at a particular time of day, this time is likely to emerge as the peak time even if only a small proportion of offences happen then.

$t_{\text {aoristic }}$ is only as accurate as the chosen unit of analysis (Ratcliffe 1999, 97). Although it is possible to use an

Table 5 Wheeler-Watson two-sample test results comparing each distribution of $t_{\text {estimate }}$ to the distribution of $t_{\text {actual }}$

\begin{tabular}{|c|c|c|c|c|}
\hline \multirow[b]{3}{*}{ Method } & \multicolumn{4}{|c|}{$W_{r}$} \\
\hline & Study area & Group I & Group II & Group III \\
\hline & $n=303$ & $n=99$ & $n=110$ & $n=94$ \\
\hline Start & $4.73^{* *}$ & $1.31^{* *}$ & $1.72^{* *}$ & $1.80^{* *}$ \\
\hline Mid-point & $1.53^{* *}$ & $0.61^{* *}$ & $0.53^{* *}$ & $0.50^{* *}$ \\
\hline End & $3.10^{* *}$ & $0.71^{* *}$ & $1.28^{* *}$ & $1.13^{* *}$ \\
\hline \multicolumn{5}{|l|}{ Known-time } \\
\hline$n\left(t_{\text {actual }}\right)=303$ & 0.06 & 0.03 & 0.05 & 0.12 \\
\hline$n\left(t_{\text {actual }}\right)=26^{a}$ & 0.08 & 0.06 & $-^{b}$ & 0.06 \\
\hline Random ${ }^{c}$ & $0.28^{* *}$ & $0.19^{*}$ & 0.08 & $0.21^{*}$ \\
\hline Aoristic (tunit $=30 \mathrm{~min})$ & $0.23^{*}$ & $0.21^{*}$ & 0.15 & $0.27^{*}$ \\
\hline
\end{tabular}

${ }^{*} p<0.05$, critical $W_{r}=0.18$.

${ }^{* *} p<0.01$, critical $W_{r}=0.27$.

a Mean value of $W_{r}$ for 1,000 runs in which the known values of $\boldsymbol{t}_{\text {known }}$ were compared against an equal number of values randomly selected from the final sample of crimes.

${ }^{b}$ Only six offences were available for known-time analysis in this group.

'Mean value of $W_{r}$ for tests on 100 distributions of $\boldsymbol{t}_{\text {random. }}$. 


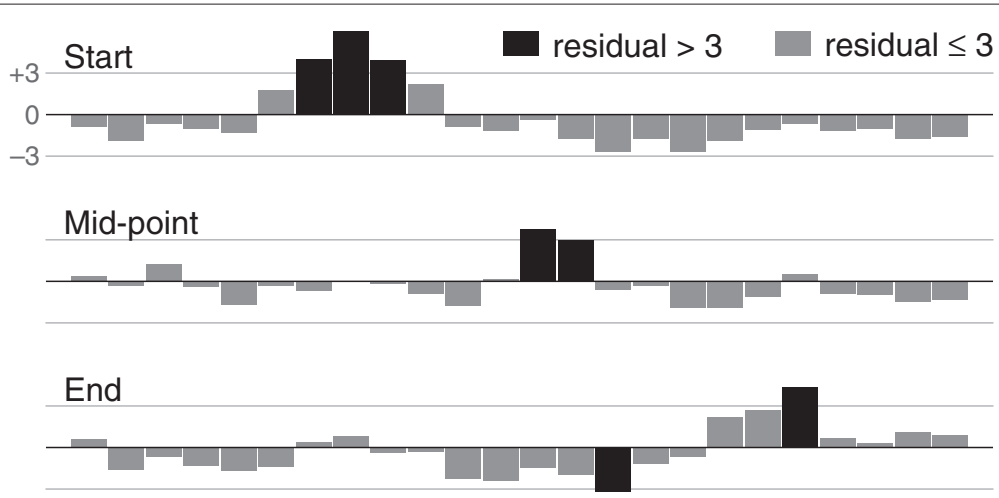

Known-time scaled so that $n=312(\approx 303)$

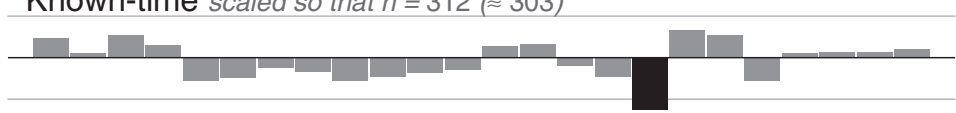

Random

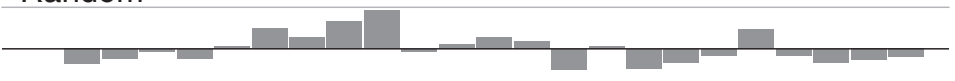

Aoristic
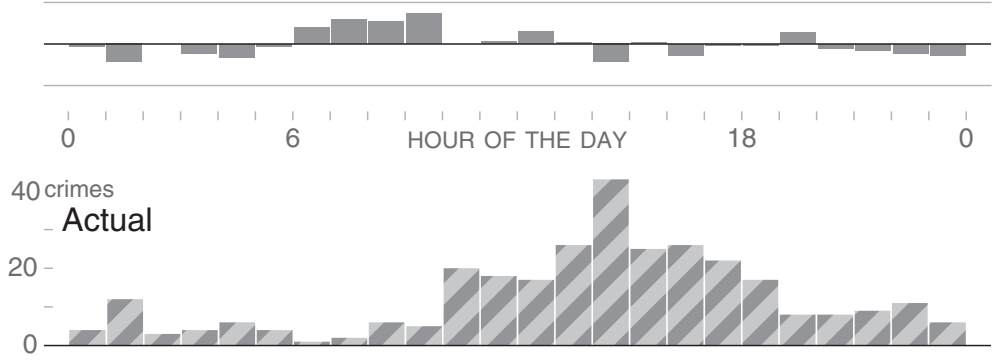

Figure 4 Standardised residual values for estimation methods showing that the start, mid-point and end methods significantly overestimate the frequency of crime at certain times of day.

infinitely small unit of analysis, the additional accuracy must be balanced against the additional processing time and effort (Ratcliffe 2000, 673). $t_{\text {unit }}$ should therefore be chosen carefully, so that peaks of activity that are shorter than $t_{\text {unit }}$ are not obscured (Johnson 2003, 450). McCue $(2007,94)$ recommends that, when the purpose of analysis is to determine when to deploy police resources, $t_{\text {unit }}$ should be set at four hours, or half a police shift. Although Koper $(1995,663)$ found that police presence was most efficient at deterring crime if officers remained in one place for only 15 minutes, Famega $(2003,158)$ found that few supervisors attempt to deploy officers so precisely.

Table 6 Optimal four-hour deployment period

\begin{tabular}{llrr}
\hline Method & Predicted period & Proportion of actual period predicted & Thefts in predicted period \\
\hline Actual & $13: 30-17: 30$ & - & $39 \%$ \\
\hline Start & $06: 30-12: 30$ & $50 \%$ & $14 \%$ \\
Mid-point & $11: 30-15: 30$ & $25 \%$ & $35 \%$ \\
End & $16: 30-20: 30$ & $50 \%$ & $20 \%$ \\
Known-time & $15: 30-19: 30$ & $62.5 \%$ & $27 \%$ \\
Random & $12: 00-16: 00$ & $75 \%$ & $35 \%$ \\
Aoristic & $12: 30-16: 30$ & & $40 \%$ \\
\hline
\end{tabular}


The modified temporal unit problem (MTUP), first mentioned by Dorling and Openshaw (1992, 640), concerns how the choice of boundaries between temporal units can artificially create and destroy clusters of offences within each unit (Taylor 2010 462; Çöltekin et al. 2011). The MTUP could compromise estimation results presented in aggregate form, for example as circular histograms (Zar 1999, 596) or wind rose charts (Brasseur 2005, 167). Aggregation can be avoided using (KDE), but not for aoristic analysis because those data are inherently aggregated. Tompson and Townsley $(2010,37)$ recommend using smaller temporal units, but very small units are likely to produce a sample distribution that is very spikey and poorly fitted to the population distribution (Schubert 2009, 42).

For these reasons, aoristic analysis may perform less well if (a) many crimes have a large $t_{\text {range }}$, (b) several crimes that occurred at the same time have a very short $t_{\text {range }}$ or (c) the unit of analysis is too corse.

The mid-point method was better at predicting peak offence times than the start or end methods, possibly because the maximum possible error of the mid-point method is half that of the other two deterministic methods. However, the mid-point method is wholy derived from the distributions of $t_{\text {start }}$ and $t_{\text {end }}$, which in turn depend entirely on the routine activities of crime victims and are unrelated to the activities of offenders. The relatively good performance of the mid-point method may be coincidental: mid-afternoon could simply be the time when a plurality of offenders came into contact with property that had been unattended since early morning. If most of the victims worked night shifts rather than day shifts, the distributions of $t_{\text {start }}$ and $t_{\text {end }}$ would be inverted and the peak time of $t_{\text {mid }}$ would be around 03:00 hours. In these circumstances, the varying availability of offenders might give a peak offence time in the evening (very close to $\left.t_{\text {start }}\right)$ and $t_{\text {mid }}$ would be misleading. This hypothesis could only be confirmed through further research into how offence frequency varies throughout $t_{\text {range }}$ for different crimes, although such research may not be worthwhile if the mid-point method is, as it appears, inferior to the aoristic and random methods.

Table 7 Comparison of the final and original samples

\begin{tabular}{lll}
\hline Method & $\boldsymbol{W}_{\boldsymbol{r}}$ & $\boldsymbol{p}$ value \\
\hline Start & 0.08 & n.s. \\
Mid-point & 0.21 & $p<0.05$ \\
End & 0.13 & n.s. \\
Random & 0.04 & n.s. \\
Aoristic (tunit & 0.13 & n.s. \\
30 minutes) & &
\end{tabular}

The distributions of $\boldsymbol{t}_{\mathrm{known}}$ for the final and original samples included the same offences and so would be identical.
The known-time method appears to be approximately as good as the mid-point method in predicting $t_{\text {actual }}$. The potential of the known-time method is that it reflects the activities of offenders; the problem is that it is based on a non-random sample of offences. There is reason to believe that the crimes available for known-time analysis will vary systematically from other crimes: Johnson et al. $(2006,13)$ found that thefts of and from motor vehicles in car parks tended to have $\bar{t}_{\text {range }}<4$ hours while thefts from other locations had longer ranges. If $t_{\text {known }}$ were based on a random sample, the results described in Section the results of the present study suggest that $t_{\text {known }}$ would be a good approximation of $t_{\text {actual }}$ where $t_{\text {actual }}$ was known for more than $10.4 \%$ of crimes.

In the present study, the known-time method included $8.5 \%$ of offences. Figure 3 suggests that this was not a random sample. In circumstances where only a rough approximation of $t_{\text {actual }}$ is required, the known-time method may be acceptable, but if the aoristic or random methods can be implemented then they should be used in preference.

The start and end methods appear to be so poor at predicting $t_{\text {actual }}$ that they are actively misleading. If we accept that the present sample is typical of aoristic crimes, this finding suggests that the start and end methods should be avoided by all analysts, even though they may occasionally predict $t_{\text {actual }}$ accurately.

A crime analyst using the results of this study to aid them in determining the most common time of day for a particular crime to occur could follow this model procedure.

1. Select an appropriate value of $t_{\text {unit }}$, which (to minimise computational resources) should be no smaller than necessary.

2. Determine if the crime is aoristic or not: since this depends on the relationship between $t_{\text {range }}$ and $t_{\text {unit }}$, a crime-type might be aoristic for small values of $t_{\text {unit }}$ but not for larger values. Findings by Ratcliffe $(2002,33)$ summarised above suggest that practitioners should use methods suitable for analysing aoristic crimes if $\bar{t}_{\text {range }}>4 t_{\text {unit }}$, whereas if $\bar{t}_{\text {range }} \leq 4 t_{\text {unit }}$ the choice of method is unlikely to influence the results.

3. If methods suitable for analysis of aoristic crimes are to be used and $t_{\text {actual }}$ can be determined for a random sample of more than $10 \%$ of crimes, use the known-time method.

4. If (as will often be the case) using the known-time method is not possible, the aoristic method should be used. Manual aoristic analysis of any more than a handful of crimes is prohibitively time-consuming, so specialist software is required (either a stand-alone package or an additional module for software such as Excel). 
5. If software is not available to perform aoristic analysis, the random method can be used as an alternative.

\section{Applicability to other crime types}

To date, the present study provides the only empirical evidence as to the relative efficacy of different estimation methods for aoristic crime, but these results are based on the study of only one crime type. It is not certain that the present results are generalisable to other types of crime, but-pending further work-the routine activities approach suggests that they might be. Analysis of the crime reports used in this study showed that most thefts occurred during the daytime while the victim was at work, and it was the routine activities of these victims that determined the distribution of $t_{\text {start }}$,

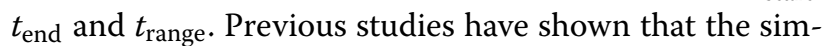
ilar temporal distributions of other aoristic crimes such as residential burglaries (Weisel 2002; Sorensen 2004) and thefts of motor vehicles from city-centre parking facilities (Rengert 1997, 210) are shaped by the same routine activities. Since the recommended estimation methods are based on $t_{\text {start }}$ and $t_{\text {end }}$, such similar distributions may well be amenable to similar methods of temporal approximation. Conversely, there may be less reason to believe in the applicability of these methods to aoristic crimes that occur mainly at night, such as graffiti (Williams and Poynton 2006, 5) or theft of vehicles from outside houses (Keister 2007, 5).

\section{Spatio-temporal interaction}

The research presented here has not considered the spatial dimension of aoristic crime in any great depth. Grubesic and Mack $(2008,287)$ note that time and space are too often separated in crime analysis, and demonstrate that time and space interact, so spatio-temporal interaction appears to be a useful avenue for further research.

Many researchers have shown that the temporal distribution of crime varies in different places. Tranter $(1985,12)$ demonstrated that the daily temporal peak in calls for service differed depending on whether a neighbourhood was primarily composed of students, workers or retired people, all of whom have different routine activities. More recently, Barthe and Stitt $(2009,146)$ found that the temporal distribution of violent crimes in areas surrounding casinos was different from that in the rest of Reno, Nevada, perhaps because the people around casinos were engaged in different actitivies from those in the rest of the city. Aoristic analysis was developed as a spatio-temporal technique to capture variations in both dimensions (Ratcliffe 2002, 41).

There are some crimes where both the offence time and location are unknown (Morgan 2010, 15). Examples include pickpocketing on public transport, theft of goods in transit by road or rail, and illegal immigrants stowing away in lorries to cross international borders (Newton 2004, 33). Gill (2007) suggested that aoristic analysis could be used to map such crimes, with an aoristic fraction being assigned to each segment of the journey during which the crime took place.

\section{Suggestions for future research}

This research analysed a single crime type in one area. Further research is required to determine if the findings here are applicable to other circumstances. Analysis of crimes that are not normally distributed in time may be particularly useful in testing whether the methods described here are generally applicable, since crime analysts will usually know nothing about the distribution of $t_{\text {actual. }}$. Bimodal temporal distributions include hourly variations in vandalism (Brower and Carroll 2007, 269) and seasonal variation in suicide among women (Kposowa and D'Auria 2010, 434), both of which can be aoristic. If data were gathered about a wide range of crime types, these could also be used to test the intuitive method, and to determine the performance of each method for samples of different sizes.

Further research would require data on the distribution of $t_{\text {actual }}$ for more aoristic crimes. Passive surveillance technologies such as CCTV and motion sensors, as well as radio-frequency identification (RFID) or global positioning system (GPS) chips embedded in vulnerable goods, are becoming increasingly common and could provide accurate offence times for aoristic crimes. Computer simulation could also be used.

At present, temporal analysis of crime using circular statistics is beyond both the skills of most analysts and the abilities of the tools available to them. A decade ago, Williamson et al. $(2000,169)$ made the same observation about spatial-analysis techniques, some of which can now be done routinely in mainstream software. Such packages need not be expensive (Dorling and Openshaw 1992, 640), especially if they are developed by a small team of publicly funded experts, as was the case with the CrimeStat program (Levine 2006, 42) now used by many agencies. Work by a single agency in this area may benefit the wider analytical community.

\section{Conclusion}

This article has suggested a random method for the temporal analysis of aoristic crime and has demonstrated the relative ability of several methods to estimate the most common offence times for one type of aoristic crime. The aoristic and random methods were most accurate, while the start and end methods were found to be misleading and should not be used.

Knowing when crimes occur is crucial to preventing them, but there are far fewer techniques available for 
temporal analysis than (for example) for spatial analysis, where many techniques have been developed in the past 15 years. There has also been less research to validate those temporal techniques that do exist. In the experience of the present authors, there are many crime analysts who-potentially as a result of this discrepancy in research output-have developed extensive skills in spatial analysis while either not conducting temporal analysis or using temporal techniques not supported by evidence.

One of the key lessons of policing research is that resources for preventing and investigating crime should be led by intelligence. Since most crimes are clustered in time, temporal analysis is necessary to ensure that deployment of such resources are effective: without knowing when crimes happen, officers are unlikely to be in the right place at the right time to prevent crime or apprehend offenders. Since many common crimes are aoristic, techniques such as those evaluated here are necessary for ensuring resources are deployed correctly. Crime analysts that choose not to use techniques designed for use with aoristic-crime data are likely to deploy resources at the wrong times, failing to prevent crime and undermining the status of intelligence-led policing. It is hoped that the findings of the present study will assist practitioners in understanding aoristic crimes such as burglaries, motor vehicle thefts and damage to property.

\section{Endnote}

a'This is because it is the victim's movement in time and space that determines the times between which the target was left unattended.

\section{Abbreviations \\ BTP: British transport police; CCTV: closed-circuit television; GPS: global positioning system; IQR: inter-quartile range; KDE: kernel density estimation; MTUP: modifiable temporal unit problem; RFID: radio-frequency identification; SPSS: Statistical package for the social sciences; UK: United Kingdom; US: United States. \\ Competing interests \\ Both authors declare that they have no competing interests. \\ Authors' contributions \\ MA prepared and analysed the data used in this study and prepared the first draft of the manuscript. KB participated in the design of the study, the statistical analysis and the writing of the manuscript. Both authors read and approved the final manuscript.}

\section{Authors' information}

KB is professor of crime science in the UCL Department of Security and Crime Science. MA is a research student at the UCL Security Science Doctoral Research Training Centre. He is a former police officer and police intelligence researcher.

\section{Acknowledgements \\ Thank you to British Transport Police for providing the data used in this research and to the anonymous reviewers for their helpful comments.}

\section{Author details}

${ }^{1}$ UCL Security Science Doctoral Research Training Centre, 35 Tavistock Square, London WC1H 9EZ, UK. ${ }^{2}$ UCL Department of Security and Crime Science, 35 Tavistock Square, London WC1H 9EZ, UK.
Received: 19 December 2012 Accepted: 3 May 2013

Published: 23 May 2013

\section{References}

Accenture. 2004. Study of Police Resource Management and Rostering Arrangements, Home Office, London.

Abuzaid, A H, I B Mohamed, and A G Hussin. 2012. Boxplot for circular variables, Computational Statistics 27, no. 3, 381-392. doi:10.1007/s00180-011-0261-5.

Barclay, G C and C Tavares. 1999. Digest 4: information on the criminal justice system in England and Wales, Home Office, London. http://rds.homeoffice. gov.uk/rds/digest4/digest4.pdf.

Barthe, E and B G Stitt. 2009. Temporal distributions of crime and disorder in casino and non-casino zones, Journal of Gambling Studies 25, no. 2, 139-152. doi:10.1007/s10899-009-9115-2.

Baumer, E and R Wright. 1996. Crime seasonality and serious scholarship: a comment on Farrell and Pease, British Journal of Criminology $\mathbf{3 6}$, no. 4 579-581. http://bjc.oxfordjournals.org/content/36/4/579.

Berens, P. 2009. CircStat: a MATLAB toolbox for circular statistics, Journal of Statistical Software 31, no. 10, 1-21. http://www.jstatsoft.org/v31/i10/ paper.

Bichler, $G$ and L Gaines. 2005. An examination of police officers'insights into problem identification and problem solving, Crime and Delinquency 51, no. 1,53-74. doi:10.1177/0011128704265936/.

Brantingham, P L and P J Brantingham. 1993. Nodes, paths and edges: considerations on the complexity of crime and the physical environment, Journal of Environmental Psychology 13, no. 1, 3-28. doi:10.1016/S0272-4944(05)80212-9.

Brasseur, L. 2005. Florence Nightingale's visual rhetoric in the rose diagrams, Technical Communication Quarterly 14, no. 2, 161-182. doi:10.1207/s15427625tcq1402_3.

Brower, A M and L Carroll. 2007. Spatial and temporal aspects of alcohol-related crime in a college town, Journal of American College Health 55, no. 5, 267-275. doi:10.3200/JACH.55.5.267-276.

Brown, DE. 1998. The Regional Crime Analysis Program (ReCAP): a framework for mining data to catch criminals, 1998 IEEE International Conference on Systems, Man, and Cybernetics, Volume 3, Institute of Electrical and Electronics Engineers, 2848-2853. doi:10.1109/ICSMC.1998.725094.

Brown, S E. 1989. Statistical power and criminal justice research., Journal of Criminal Justic 17, no. 2, 115-122. doi:10.1016/0047-2352(89)90004-4

Brunsdon, C and J Corcoran. 2006. Using circular statistics to analyse time patterns in crime incidence, Computers, Environment and Urban Systems 30, no. 3, 300-319. doi:10.1016/j.compenvurbsys.2005.11.001.

Buskirk, TD. 1998. Nonparametric density estimation using complex survey data. http://www.amstat.org/sections/SRMS/proceedings/papers/1998_136.pdf.

Chiu, S T. 1996. A comparative review of bandwidth selection for kernel density estimation, Statistica Sinica 6, 129-146. http://www3.stat.sinica.edu.tw/ statistica/oldpdf/A6n18.pdf.

Cohen, L E and M Felson. 1979. Social change and crime rate trends: a routine activity approach, American Sociological Review 44, no. 4, 588-608. http:// www.jstor.org/stable/2094589.

Cohn, E G. 1993. The prediction of police calls for service: the influence of weather and temporal variables on rape and domestic violence, Journal of Environmental Psychology 13, no. 2, 71-83. doi:10.1016/S0272-4944(05)80216-6.

Cohn, E G and J Rotton. 2003. Even criminals take a holiday: instrumental and expressive crimes on major and minor holidays, Journal of Criminal Justice 31, no. 4, 351-360. doi:10.1016/S0047-2352(03)00029-1.

Çöltekin, A, S De Sabbata, C Willi, I Vontobel, S Pfister, M Kuhn, and M Lacayo. 2011. Modifiable temporal unit problem. ICA Commission on GeoVisualization, Paris: International Cartographic Association. http:// geoanalytics.net/ica/icc2011 workshop.htm.

Di Marzio, M, A Panzera, and CC Taylor. 2011. Kernel density estimation on the torus, Journal of Statistical Planning and Inference 141, no. 6, 2156-2173. doi:10.1016/j.jspi.2011.01.002

Dorling, D and S Openshaw. 1992. Using computer animation to visualize space-time patterns, Environment and Planning, Series B: Planning and Design 19, no. 6, 639-650. doi:10.1068/b190639. 
Famega, C N. 2003. Discretion or direction? An analysis of patrol officer downtime, PhD thesis, University of Cincinnati,Cincinnati. http://cech.uc.edu/content/ dam/cech/programs/criminaljustice/docs/phd_dissertations/2003/ Famega.pdf.

Federal Bureau of Investigation. 2011. Crime in the United States 2010, Federal Bureau of Investigation, Washington. http://www.fbi.gov/about-us/cjis/ ucr/crime-in-the-u.s/2010/crime-in-the-u.s.-2010.

Felson, M. 2006. Crime and Nature, Sage, Thousand Oaks.

Felson, M and E Poulsen. 2003. Simple indicators of crime by time of day, International Journal of Forecasting 19, no. 4, 595-601. doi:10.1016/S0169-2070(03)00093-1.

Fisher, N I. 1993. Statistical Analysis of Circular Data, Cambridge University Press, Cambridge.

Fitzpatrick, T. 2004. Social policy and time, Time and Society 13, no. 2/3, 197-219. doi:10.1177/0961463X04043502

Gill, A. 2007. Developing aoristic network analysis upon London's transport system, Jill Dando Institute of Security and Crime Science, London. http://www.ucl. ac.uk/jdi/events/mapping-conf/conf-2007/conf-pres2007/pres16.

Gottlieb, S, S I Arenberg, and R Singh. 1994. Crime analysis: from first report to final arrest, San Bernardino, Alpha.

Grubesic, TH and E A Mack. 2008. Spatio-temporal interaction of urban crime, Journal of Quantitative Criminology 24, no. 3, 285-306.

Harvill, L M. 1991. An NCME instructional manual on standard error of measurement, Educational Measurement: issues and practice 10, no. 2, 33-41. doi:10.1111/j.1745-3992.1991.

Hawley, A H. 1950. Human Ecology: a theory of community structure, Ronald Press, New York

Helms, D. 2008. Temporal analysis (SL Gwinn, C Bruce, JP Cooper, and S Hick, eds.), International Association of Crime Analysts, Overland Park.

Hoare J. 2011. Acquisitive and other property crime (R Chaplin, J Flatley, and K Smith, eds.), no. 10/11 in Home Office Statistical Bulletin series, first edition. Home Office.

Home Office. 2011. Recorded crime data by basic command unit, community safety partnership areas and local authorities_Crime in England and Wales 2010/11. https://www.gov.uk/government/uploads/system/uploads/ attachment_data/file/116417/hosb1011.pdf.

Johnson, S D and KJ Bowers. 2004. The stability of space-time clusters of burglary, British Journal of Criminology 44, no. 1, 55-65. doi:10.1093/bjc/44.1.55.

Johnson, S D, L Summers, and K Pease. 2006. Vehicle Crime: Communicating Spatial and Temporal Patterns, Final Report, Jill Dando Institute of Crime Science, London.

Jammalamadaka, SR and A SenGupta. 2001. Topics in Circular Statistics. No. 5 in Series on Multivariate Analysis, World Scientific, Singapore.

Jones, M C, J S Marron, and S J Sheather. 1996. A brief survey of bandwidth selection for density estimation, Journal of the American Statistical Association 91, no. 433, 401-407. http://www.jstor.org/stable/2291420.

Johnson, I. 2003. Aoristic analysis: seeds of a new approach to mapping archaeological distributions through time, Archaeopress, in BAR International Series. Oxford.

Keister, T. 2007. Thefts of and from Cars on Residential Streets and Driveways. No. 46 in Problem-Oriented Guides for Police Problem-Specific Guides Series, US Department of Justice, Washington,DC. http://www.popcenter.org/ problems/residential_car_theft/.

Koper, C S. 1995. Just enough police presence: reducing crime and disorderly behaviour by optimizing patrol time in crime hotspots, Justice Quarterly 12 no. 4, 649-672. http://heinonline.org/HOL/Page?collection= journals\&handle=hein.journals/jquart12\&id $=673$.

Kposowa, A J and S D'Auria. 2010. Association of temporal factors and suicides in the United States, 2000-2004, Social Psychiatry and Psychiatric Epidemiology 45, no. 4, 433-445. doi:10.1007/s00127-009-0082-9.

Levine, N. 2006. Crime mapping and the Crimestat program, Geographical Analysis 38, no. 1, 41-56. doi:10.1111/j.0016-7363.2005.00673.x

Lewis, C. 1992. Crime statistics: their use and misuse (T Griffin, ed.), Central Statistical Office, London.

Mardia, KV. 1972. Statistics on Directional Data. No. 13 in Probability and Mathematical Statistics: a series of monographs and textbooks, Academic Press, London.

McCahill, M and C Norris. 2003. CCTV systems in London: their structure and practices. No. 10 in Urban Eye Working Papers series, Berlin: Zentrum Technik und Gesellschaft,Technische Universität Berlin. http://www.urbaneye.net/ results/ue_wp10.pdf.

McCue, C. 2007. Data Mining and Predictive Analysis: intelligence gathering and crime analysis, Burlington, Butterworth-Heinemann.

McLaughlin, L M, S D Johnson, KJ Bowers, D J Birks, and K Pease. 2007. Police perceptions of the long-and short-term spatial distribution of residential burglary, International Journal of Police Science and Management 9, no. 2, 99-111.

Melbin, M. 1978. City rhythms (JT Fraser, N Lawrence, and D Park, eds.), Springer, New York.

Messner, S F and K Tardiff. 1985. The social ecology of urban homicide: an application of the "routine activities" approach, Criminology 23, no. 2, 241-267. doi:10.1111/j.1745-9125.1985.

Moore, B R. 1980. A modification of the Rayleigh test for vector data, Biometrika 67, no. 1, 175-180. http://www.jstor.org/pss/2335330.

Morgan, J D. 2010. A visual time-geographic approach to crime mapping. PhD thesis, Florida State University,Tallahassee,FL. http://etd.lib.fsu.edu/theses/ available/etd-11012010-214122/unrestricted/ Morgan_J_Dissertation_2010.pdf.

Nelson, A L, R D F Bromley, and C J Thomas. 2001. Identifying micro-spatial and temporal patterns of violent crime and disorder in the British city centre, Applied Geography 21, no. 3, 249-274. doi:10.1016/S0143-6228(01)00008-X.

Newton, A D. 2004. Crime on public transport: 'static' and 'non-static' (moving) crime events, Western Criminology Review 5, no. 3, 25-42. http://wcr. sonoma.edu/v5n3/manuscripts/newton.pdf.

O'Shea, T C and K Nicholls. 2003. Crime Analysis in America: findings and recommendations, US Department of Justice, Washington. http://cops. usdoj.gov/CDROMs/Tribal/stats/CrimeAnalysisAmericaFindings.pdf.

Ratcliffe, JH. 1999. The genius loci of crime: revealing associations in time and space, $\mathrm{PhD}$ thesis, University of Nottingham,Nottingham.

Ratcliffe, J H. 2000. Aoristic analysis: the spatial interpretation of unspecific temporal events, International Journal of Geographical Information Science 14, no. 7, 669-679. http://www.ingentaconnect.com/content/tandf/tgis/ 2000/00000014/00000007/art00004.

Ratcliffe, JH. 2001. Policing Urban Burglary. No. 213 in Trends and Issues in Crime and Criminal Justice series, Australian Institute of Criminology, Canberra. http://www.aic.gov.au/publications/current\%20series/tandi/201-220/ tandi213.html.

Ratcliffe, JH. 2002. Aoristic signatures and the spatio-temporal analysis of high volume crime patterns, Journal of Quantitative Criminology 18, no. 1, 23-43. doi:10.1023/A:1013240828824.

Ratcliffe, J H. 2004. Geocoding crime and a first estimate of a minimum acceptable hit rate, International Journal of Geographical Information Science 18, no. 1, 61-72. doi:10.1080/1365881031000596076.

Ratcliffe, J H and M J McCullagh. 1998. Aoristic crime analysis, International Journal of Geographical Information Science 12, no. 7, 751-764. doi:10.1080/136588198241644.

Ratcliffe, JH and M J McCullagh. 2001. Chasing ghosts? Police perception of high crime areas, British Journal of Criminology 41, no. 2, 330-341. doi:10.1093/bjc/41.2.330.

Rayment, M R. 1996. Spatial and temporal crime analysis techniques. No. TM/06/96 in Technical Memorandum series, Canadian Police Research Centre,Ottawa. http://cradpdf.drdc-rddc.gc.ca/PDFS/unc76/p530054.pdf.

Rengert, G. 1997. Auto theft in central Philadelphia (R Homel, ed.), Criminal Justice Press, NY. http://www.popcenter.org/library/crimeprevention/ volume_07/08_rengert.pdf.

Schubert, JL. 2009. Incorporating time and daily activities into an analysis of urban violent crime, University of Texas at Dallas, PhD thesis.

SenGupta, S and J S Rao. 1966. Statistical analysis of cross-bedding azimuths from the Kamthi Formation around Bheemaram, Pranhita: Godavari Valley, Sankhyā: the Indian Journal of Statistics,Series B 28, no. 1/2, 165-174. http://www.jstor.org/stable/25051567.

Skogan, W G. 1974. The validity of official crime statistics: an empirical investigation, Social Science Quarterly 55, no. 1, 25-38.

Sorensen, D W M. 2004. Temporal Patterns of Danish Residential Burglary, Copenhagen,Justits Ministeriet. http://justitsministeriet.dk/sites/default/ files/media/Arbejdsomraader/Forskning/Forskningspuljen/2011/2004/ Temporal_Patterns_of_Danish_Residential_Burglary.pdf.

Spatz Widom, C. 1989. The cycle of violence, Science 244, no. 4901, 160-166. http://www.jstor.org/stable/1702789. 
Taylor, R B. 2010. Communities, crime, and reactions to crime multilevel models: accomplishments and meta-challenges, Journal of Quantitative Criminology 26, no. 4, 455-466. doi:10.1007/s10940-010-9114-6.

Tilley, N. 1995. Thinking about Crime Prevention Performance Indicators. No. 57 in Crime Detection and Prevention Series, Home Office, London.

Tompson, L and M Townsley. 2010. (Looking) back to the future: using space-time patterns to better predict the location of street crime, International Journal of Police Science and Management 12, no. 1, 23-40. doi:10.1350/ijps.2010.12.1.148.

Townsley, M, R Homel, and J Chaseling. 2000. Repeat burglary victimisation: spatial and temporal patterns, The Australian and New Zealand Journal of Criminology 33, no. 1, 37-63. doi:10.1177/000486580003300104.

Tranter, P J. 1985. Intra-urban variability in rhythms of pathological events, Geografiska Annaler, Series B: Human Geography 67, no. 1, 7-14. http:// www.jstor.org/stable/490793.

Turlach, B A. 1993. Bandwidth selection in kernel density estimation: a review. Working paper. Institut für Statistik und Ökonometrie, Humboldt Universität zu ,Berlin, Berlin. http://EconPapers.repec.org/RePEc:wop:humbse:9307.

Walker, C. 2009. Neighbor terrorism and the all-risks policing of terrorism, Journal of National Security Law and Policy 3, 121-377. http://jnslp.com/2009/12/ 15/neighbor-terrorism-and-the-all-risks-policing-of-terrorism/.

Watson, G S. 1961. Goodness-of-fit tests on a circle, Biometrika 48, no. 1/2, 109-114. http://www.jstor.org/stable/2333135.

Watson, GS. 1962. Goodness-of-fit tests on a circle ll, Biometrika 49, no. 1/2, 57-63. http://www.jstor.org/stable/2333467.

Weisel, D L. 2002. Burglary of Single-Family Houses. No. 18 in Problem-Oriented Guides for Police Series, US Department of Justice, Washington. http://www. popcenter.org/problems/burglary_home/.

Wheeler, S and G S Watson. 1964. A distribution-free two-sample test on a circle, Biometrika 51, no. 1/2, 256-257. http://www.jstor.org/stable/2334214.

Williams, S and S Poynton. 2006, Trends in Recorded Incidents of Graffiti in New South Wales 1996-2005, No. 34 in Crime and Justice Statistics Bureau Brief series, NSW Bureau of Crime and Statistics Research. http://www.bocsar. nsw.gov.au/lawlink/bocsar/ll_bocsar.nsf/vwFiles/BB34.pdf/\$file/BB34.pdf.

Williamson, D, T A Ross, S McLafferty, and V Goldsmith. 2000. Evaluating statistical software for analysing crime patterns and trends (V Goldsmith, PG McGuire, and JH Mollenkopf, eds.), Sage, Thousand Oaks.

Zar, J H. 1999. Biostatistical Analysis, fourth edition, Upper Saddle River, Prentice Hall.

doi:10.1186/2193-7680-2-1

Cite this article as: Ashby and Bowers: A comparison of methods for temporal analysis of aoristic crime. Crime Science 2013 2:1.

\section{Submit your manuscript to a SpringerOpen ${ }^{\mathcal{O}}$ journal and benefit from:}

- Convenient online submission

- Rigorous peer review

- Immediate publication on acceptance

- Open access: articles freely available online

- High visibility within the field

- Retaining the copyright to your article

Submit your next manuscript at $\boldsymbol{~ s p r i n g e r o p e n . c o m ~}$ 